\title{
Ontogenic Resistance and Plant Disease Management: A Case Study of Grape Powdery Mildew
}

\author{
Andrea Ficke, David M. Gadoury, and Robert C. Seem
}

\begin{abstract}
Department of Plant Pathology, Cornell University, New York State Agricultural Experiment Station, Geneva 14456.
Current address of A. Ficke: Department of Plant Pathology, Wageningen University, P.O. Box 8025, Binnenhaven 5, Wageningen 6709, The Netherlands.

Accepted for publication 12 February 2002.
\end{abstract}

\section{ABSTRACT}

Ficke, A., Gadoury, D. M., and Seem, R. C. 2002. Ontogenic resistance and plant disease management: A case study of grape powdery mildew. Phytopathology 92:671-675.

A fundamental principle of integrated pest management is that actions taken to manage disease should be commensurate with the risk of infection and loss. One of the less-studied factors that determines this risk is ontogenic, or age-related resistance of the host. Ontogenic resistance may operate at the whole plant level or in specific organs or tissues. Until recently, grape berries were thought to remain susceptible to powdery mildew (Uncinula necator) until late in their development. However, the development of ontogenic resistance is actually quite rapid in berries, and fruit become nearly immune to infection within 4 weeks after fruit set. Our objective was to determine how and at what stage the pathogen was halted in the infection process on ontogenically resistant berries. Adhesion of conidia, germination, and appressorium formation were not impeded on older berries. However, once berries were approximately 3 weeks old and older, few germlings were able to form secondary hyphae. Ontogenically resistant berries responded rapidly to infection by synthesis of a germin-like protein that had been previously shown to play a role in host defense against barley powdery mildew. On susceptible berries, cell discoloration around penetration sites indicated the oxidation of phenolic compounds; a process that was followed by localized cell death. However, the pathogen was still able to infect such cells prior to their death, continue secondary growth, and thereby colonize young

Ontogenic or age-related resistance describes the ability of whole plants or plant parts to resist or tolerate disease as they age and mature. It may not lead to immunity, but levels of resistance that develop during aging of plant tissue may greatly affect eventual disease severity and may even lead to escape from infection. For example, bean seedlings are highly susceptible to damping off, caused by Pythium ultimum, during the first 6 days after emergence. Later, infection may still lead to some root necrosis but will not result in the collapse of the entire plant (G. Abawi, Cornell University, Geneva, personal communication). Strawberries rot due to Botrytis cinerea infections during flowering, but they become more resistant to infection later in their development (3). Similarly, young apple leaves and fruit are highly susceptible to scab (Venturia inaequalis) but become more resistant to infection as they mature $(5,10,11)$. In many pathosystems, ontogenic

Corresponding author: D. M. Gadoury; E-mail address: dmg4@ cornell.edu

Publication no. P-2002-0325-010

(c) 2002 The American Phytopathological Society berries. Formation of papillae was not involved in the differential resistance mechanism of older berries. In susceptible berries, papillae formed frequently at infection sites but did not always contain the pathogen, whereas in resistant berries, the pathogen was always halted prior to the formation of papillae. The host defense, which conditions ontogenic resistance, operates in the earliest stages of the infection process, in the absence of gross anatomical barriers, prior to the formation of a functional haustorium and prior to the development of a conspicuous penetration pore. We also found that diffuse powdery mildew colonies that were not visible in the field predisposed berries to bunch rot by Botrytis cinerea, increased the levels of infestation by spoilage microorganisms, and substantially degraded wine quality. Our improved understanding of the nature, causes, and stability of ontogenic resistance in the grapevine/ powdery mildew system has supported substantial changes in how fungicides are used to control the disease. Present applications are more focused on the period of maximum fruit susceptibility instead of following a calendar-based schedule. This has improved control, reduced losses, and in many cases reduced the number of fungicide applications required to suppress the disease. Particularly where fungicides are deployed in a programmatic fashion and ontogenic resistance is dynamic, there may be equivalent improvements to be made in other hostpathogen systems through studies of how host susceptibility changes through time.

Additional keywords: adult plant resistance, Vitis. resistance is quite commonly observed and noted. It is less commonly integrated in disease management systems, though. A fundamental principle of integrated pest management (IPM) is the alignment of control measures with the actual risk of infection and potential for loss. It seems that knowledge of ontogenic resistance is an under utilized resource in devising IPM strategies that could be used to improve plant disease management.

Ontogenic resistance as a component of risk: the apple scab pathosystem. Venturia inaequalis, the causal agent of apple scab, overwinters on the orchard floor and discharges airborne ascospores during spring rains as the apple clusters emerge, expand, and mature. Falk et al. (5) and Gadoury et al. $(10,11)$ have described a means by which a quantitative estimate of the risk of infection can be generated from measurements of the area of susceptible tissue as it expands (Fig. 1A), the decrease in leaf susceptibility (Fig. 1B), and the density of ascosporic inoculum available in the field (Fig. 1C). These three factors expressed on a 0 -to-1 scale can be multiplied together to estimate the distribution of risk (Fig. 1D). This distribution has described the actual disease risk in the field quite accurately $(5,10,11)$. A similar model was also de- 
scribed by Aylor (2). In this case, ontogenic resistance is a critical component of an integrated approach to quantifying the risk of infection. The resultant distribution of risk (Fig. 1D) is strikingly different from the distributions of any of the three risk factors considered in isolation (Fig. 1A to C). Consequently, an approach to manage apple scab that does not consider ontogenic resistance (as well as the other components) is likely to be misaligned with the actual risk of disease.

Ontogenic resistance in the grape powdery mildew pathosystem. Grapes are the most widely planted fruit crop in the world and many of their most devastating diseases require the intensive use of fungicides. Uncinula necator, the causal agent of powdery mildew, is one of the most destructive pathogens on grapevines, colonizing leaves, rachis, and fruit of the vine, reducing yield and wine quality substantially. Despite intensive fungicide use, mediocre disease control has sometimes been observed in the field due to a misalignment between fruit susceptibility and timing of fungicide applications. Gadoury and Seem (7) and Gadoury et al. (12,13) showed that grapes of all tested cultivars display a rather narrow window of fruit susceptibility centered around bloom. Only berries inoculated within 3 weeks of bloom developed severe dis-
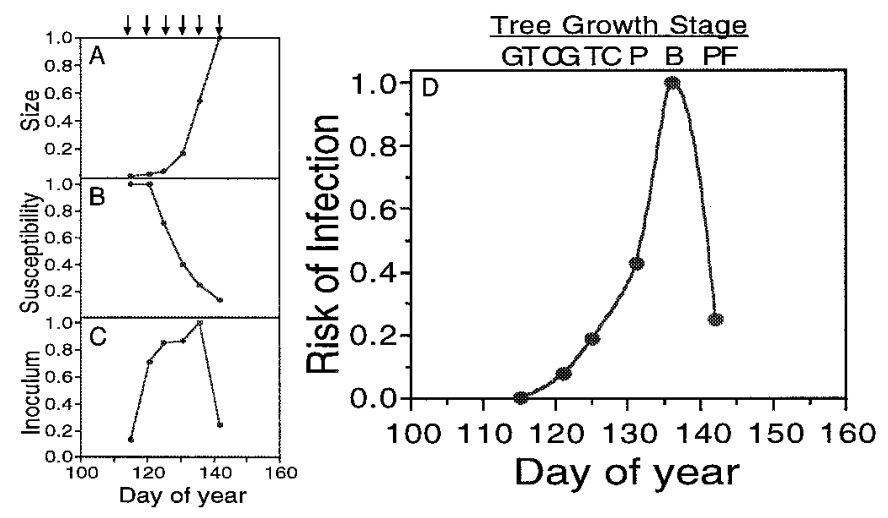

Fig. 1. A to D, Components involved in predicting the relative risk of infection. A, Changes in leaf cluster size of apples over time, B, susceptibility of apple leaves to Venturia inaequalis, and $\mathbf{C}$, the amount of airborne Venturia inaequalis inoculum in the field with growth stage of McIntosh trees. $\mathbf{D}$, The product of $\mathbf{A}, \mathbf{B}$, and $\mathbf{C}$ is the relative risk of infection.

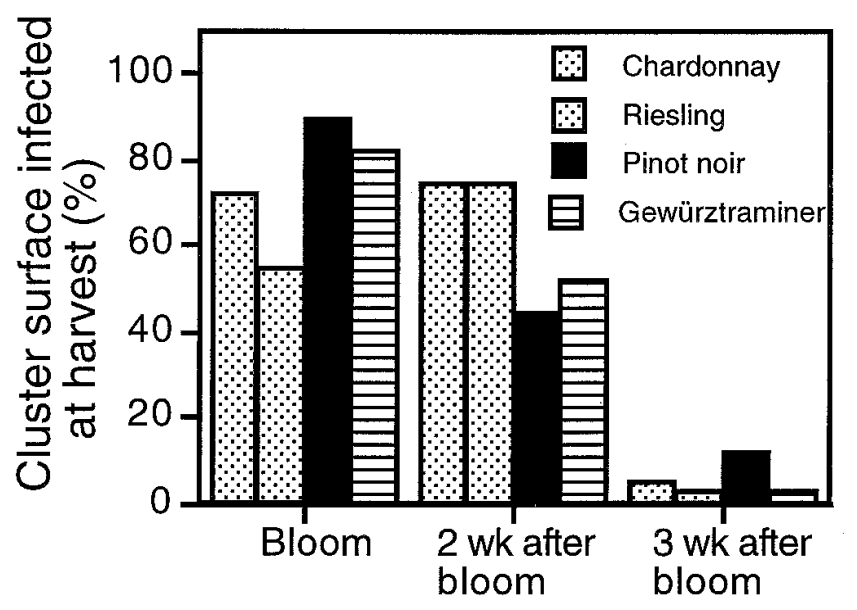

\section{Fruit growth stage at inoculation}

Fig. 2. Susceptibility of grape berries of four Vitis vinifera cultivars to infection by Uncinula necator at various stages of development. Berries were inoculated with a conidial suspension at the indicated stages, and disease severity was assessed at harvest. Values are the means of two growing seasons. Bars indicate one standard error of the mean. ease symptoms (Fig. 2). The mechanism of this ontogenic resistance was poorly understood. Delp (4) suggested cuticle thickness or soluble solid levels in berries as possible defense mechanisms. Accumulation of soluble solids has since been shown to lag behind the development of ontogenic resistance by several weeks $(7,12)$. Understanding the mechanism of ontogenic resistance and its consistency under a variety of conditions would allow us to better predict its ultimate effect on disease progress, and thereby better align control measures with the risk of yield loss.

The objectives of our research, presented briefly in this paper, were to precisely define the onset of ontogenic resistance and to describe its mechanism at the anatomical, biochemical, and molecular level, as well as to describe the effect of ontogenic resistance on pathogen development.

Where is the pathogen stopped? Detached grape berries of the North American grape species Vitis labruscana 'Concord' and the European grape species Vitis vinifera 'Chardonnay' were inoculated during their susceptible and resistant phases with conidia of $U$. necator using a spore-settling tower. The density of the conidia deposited was determined microscopically immediately after inoculation. Berries were incubated for $24 \mathrm{~h}$ while exposed to a standardized stream of air. The density of the deposited conidia was counted again to determine if spores attached more tenaciously to susceptible berries than to resistant ones. However, there was no significant difference in spore retention between susceptible and resistant berries.

To compare early fungal development on old versus young berries, we assessed germination, appressorium formation, and hyphal establishment 1 and 3 days after inoculation. Again, no significant difference was found in percent germination or appressorium formation between either treatment. However, powdery mildew conidia failed to form secondary hyphae on resistant berries, while 40 to $60 \%$ of conidia that had formed appressoria proceeded to form secondary hyphae and continued to colonize susceptible berries. Hence, the pathogen was stopped sometime after the formation of an appressorium but before it was able to form secondary hyphae.

Fungal development depends on the penetration of the host cuticle and cell wall followed by the successful establishment of haustoria. Susceptible and resistant berries were sampled 1 day after inoculation and hand sectioned. These sections were fixed in lactophenol/ethanol, cleared, and mounted in methylsalicylate. Differential interference contrast microscopy was used to observe penetration holes at the surface of epidermal cells, and haustoria within the cells. We found 90 to $100 \%$ of all conidia that formed appressoria were also able to produce a visible penetration pore beneath the appressorium (Fig. 3A) on susceptible berries, but only 1 to $2 \%$ did so on resistant berries. No haustoria were observed in resistant berries 1 day after inoculation. It appears that the pathogen is stopped before the cuticle and cell wall of resistant

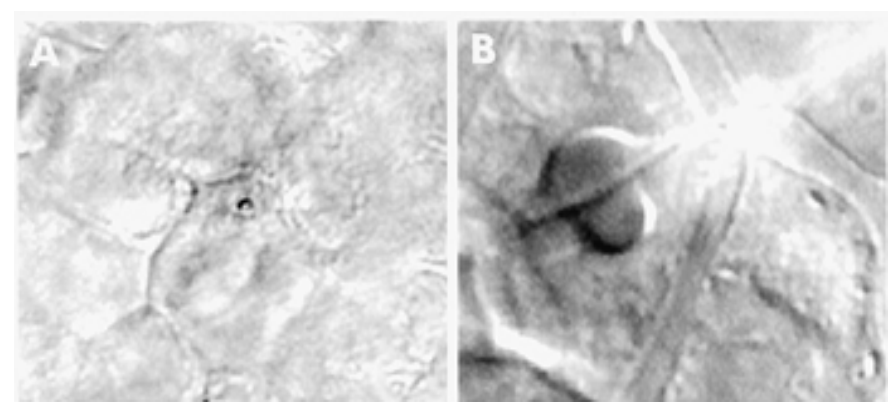

Fig. 3. A and B, Differential interference contrast micrographs of penetration pore and papillum formation on epidermal cells of 1-week-old 'Chardonnay' berries at 24-h postinoculation. Detached berries were inoculated via a spore settling tower. A, Penetration pore in focal plane beneath appressorium of Uncinula necator. B, Papillum formed beneath appressorium on grape berry cuticle. 
berries is penetrated. Whether the failure to penetrate is due to a physical or chemical barrier in the cuticle or cell wall, induced synthesis of an inhibitory compound by host cells, or the lack of a recognition factor remains unclear.

Potential host barriers in resistant berries. After formation of the appressorium, the first barriers that must be breached by the pathogen are the cuticle and the cell wall. The thickness of both was measured during early berry development in 'Concord' and 'Chardonnay'. While cuticular thickness increased as berries matured, the magnitude of the increase is not commensurate with the degree of resistance that develops in older berries. Furthermore, the cuticular thickness of young 'Concord' berries (susceptible) was greater than that of older (resistant) 'Chardonnay' berries. Cell wall thickness in berries did not vary significantly over the first 4 weeks of berry development. Resistance in older berries is therefore unlikely to be linked to cuticle or cell wall thickness. However, changes in ultrastructure or chemical composition of cuticle and cell wall might be important in stopping ingress of the pathogen. These factors have not yet been investigated.

Induced defense structures, such as papillae, have been reported to play a role in resistance against barley powdery mildew (1). Papillae are cell wall appositions formed between the cell wall and the plasmalemma at penetration sites, and consist mainly of $\beta$-glucans and phenolic compounds. Both susceptible and resistant berries were inoculated, sampled after 1 day, cleared, and examined microscopically to quantify this defense response. We found papillae at 70 to $80 \%$ of all infection sites on susceptible berries (Fig. 3B), but none were formed on resistant berries inoculated with powdery mildew. These results suggest that papillae are not always effective defense barriers, allowing powdery mildew to progress on susceptible berries. It also shows that papillae are not relevant to stopping the pathogen on resistant fruit.

Susceptible berries display a halo of strong autofluorescence around the infection sites 18 to $24 \mathrm{~h}$ after inoculation under nearUV light (Fig. 4). The autofluorescence indicates accumulation of phenolics in susceptible berries preceding papillum formation. Autofluorescent halos around infection sites are missing in the

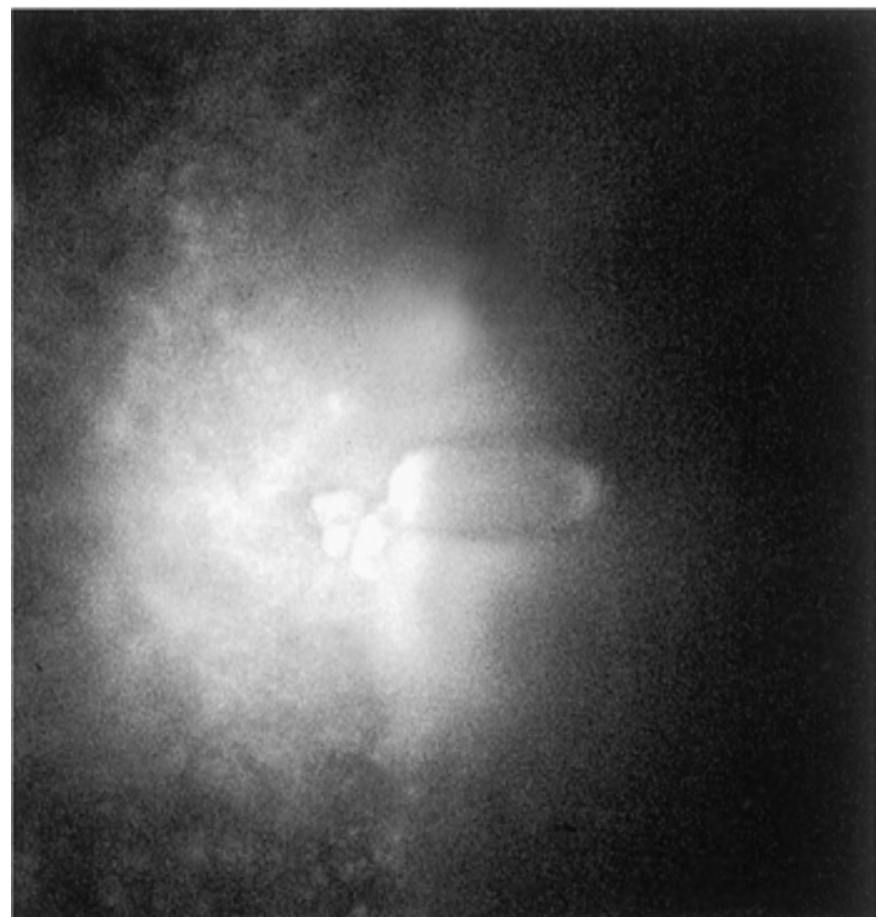

Fig. 4. Autofluorescence of phenolic compounds around infection sites of Uncinula necator in grape berries. Epidermal cells of 1-week-old berries synthesized phenolics that fluoresced under near-UV light 18 - to 22-h postinoculation. resistant fruit, possibly due to the lack of penetration that might trigger this host response in susceptible berries. Within $24 \mathrm{~h}$ after inoculation of susceptible berries, autofluorescent cells surrounding infection sites turn amber and eventually brown. This discoloration is probably due to oxidation of phenolics accumulating in the tissue. Discolored areas expand over time and are associated with almost every appressorium along the hyphal strand (Fig. 5). The impact of this cell response upon pathogen growth remains unclear. Powdery mildew colonies continue to expand despite accumulation of phenolics and discoloration at infection sites on susceptible berries.

Gross anatomical or morphological changes during berry development, therefore, do not appear to account for the substantial changes that are observed in resistance as berries mature, and the

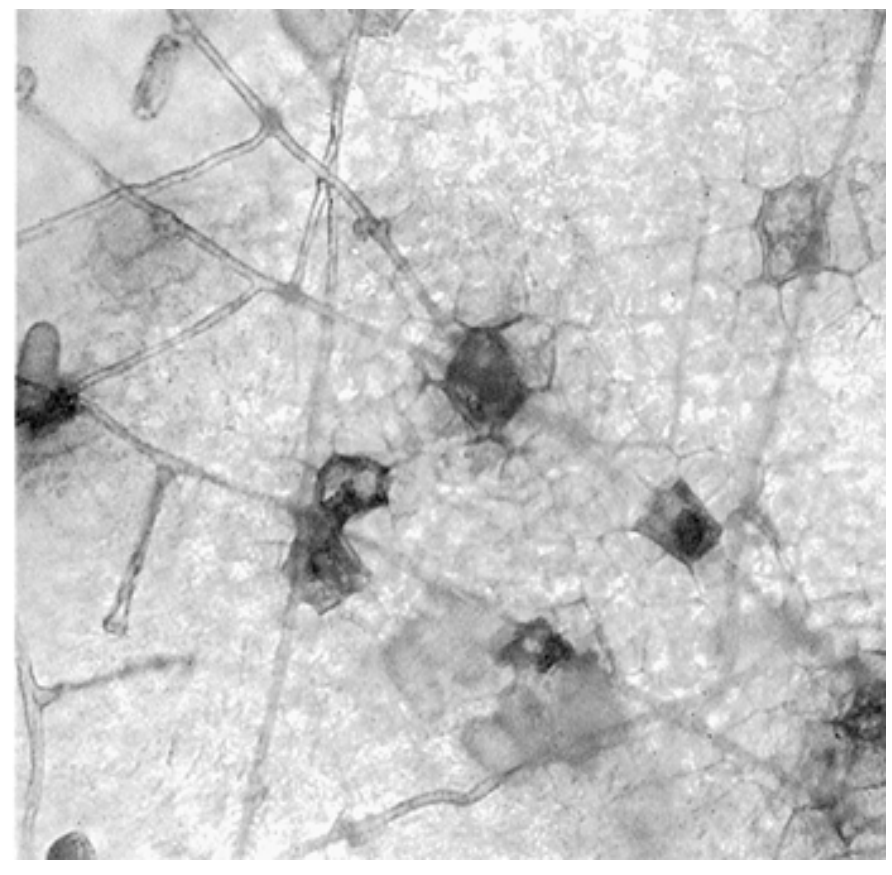

Fig. 5. Discoloration of epidermal cells of a 2.5-week-old berry at infection sites of Uncinula necator along the hyphal strand 2 weeks after inoculation. The first signs of cell discoloration beneath appressoria appeared 24 to $48 \mathrm{~h}$ after inoculation.

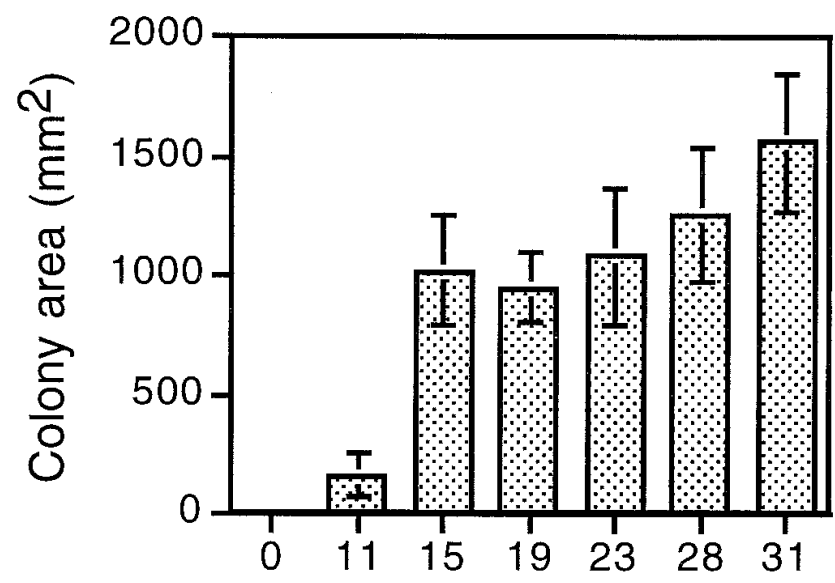

Time after inoculation (days)

Fig. 6. Colony growth of powdery mildew on grape berries. Berries were inoculated at 1 week post fruit set and examined for colony development in 4-day intervals starting 11 days after inoculation. The colony growth was most rapid during the first 2 weeks, and slowed thereafter, just as ontogenic resistance was strongly expressed. 
pathogen appears to be halted at, or very near, the interface between appressorium and cuticle. However, extraction of RNA from berry skins collected at different time intervals after inoculation did show a molecular response to powdery mildew inoculations in resistant fruit. Reverse transcription-polymerase chain reaction of the extracted RNA showed expression of a germin-like protein at 16, 20,24, and $48 \mathrm{~h}$ after inoculation in resistant but not in susceptible or uninoculated control berries. The germin-like protein gene was reported to be involved in the defense response of the wheat powdery mildew system (14). Early expression of such a gene indicates a rapid host response, which might initiate a cascade of reactions that could lead eventually to berry resistance. The actual role of this gene in grapevines has not yet been identified and is still subject to speculation.

Effect on colony development. Despite the lack of new infections on 4-week-old resistant grape berries, powdery mildew colonies may become more conspicuous after that period in the field. Colony expansion was followed on 'Concord' and 'Chardonnay' berries inoculated at various stages of growth over several weeks by estimating the berry surface area covered with powdery mildew at 3 - to 4 -day intervals under $\times 10$ to $\times 40$ magnification. Colonies expanded rapidly during the first week after inoculation of 2-week-old berries, but no significant growth occurred thereafter (Fig. 6). Within these aging mildew colonies, the viability of hyphae was monitored over time using the fluorescent vital stain fluorescein diacetate. The percentage of viable hyphae within the colony continually declined as the berry aged (Fig. 7). We also found that the pathogen produced more appressoria per micrometer of hyphae as berries aged, maybe to compensate the increased failure to penetrate and become successfully established within epidermal cells of older berries. Finally, we found that the latent period increased by 10 to $18 \%$ as berries began to express ontogenic resistance

Collectively, these findings suggest that it becomes increasingly difficult for the fungus to penetrate and survive upon the epidermis of older berries, although the conidia deposited on such berries germinate and form appressoria. Failure to penetrate the epidermis may require the pathogen to expend additional resources in repeated attempts to pierce the cuticle without additional hyphal growth. The rate of hyphal elongation, and hence colony expansion declines and hyphal mortality increases as ontogenic resistance is strongly expressed. Disease progress is slowed and

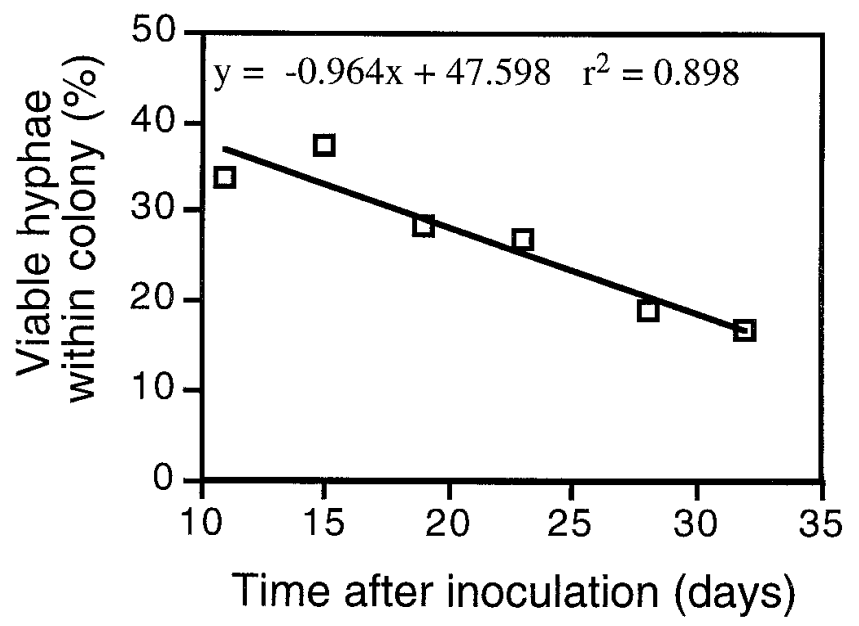

Fig. 7. Loss of viable hyphae from within powdery mildew colonies as berries age. 'Chardonnay' berries were inoculated 1 week after bloom and sampled in 4-day intervals starting 11 days after inoculation. Tangential berry sections were stained with the vital stain fluorescein diacetate for 5 min and observed under fluorescent light. The percentage of viable hyphae within the colony was estimated for each berry at the indicated sampling times. eventually stopped because there is less fungal biomass to support sporulation, and the latent period is increased. Disease progress is finally stopped entirely because the berry becomes nearly immune to infection, and the remaining hyphae within the colony die.

Interaction of powdery mildew with other microorganisms on grape berries. Although berries begin to strongly express ontogenic resistance around 3 weeks after fruit set, infection results in diffuse, nonsporulating colonies hardly visible to the unaided eye (6). This type of diffuse infection predisposes the fruit to bunch rot, possibly by creating entrance points for $B$. cinerea, the causal agent of bunch rot. Diffuse infections of grape berries can result in the development of an epiphytic microflora that is associated with reduced wine quality $(8,9)$, including spoilage microorganisms such as lactic acid bacteria and yeasts in the genera Dekkera, Kloeckera, and Brettanomyces. Berries supporting diffuse powdery mildew colonies may appear perfectly healthy in the vineyard, but the associated microorganisms may impart a very foul flavor when used to make wine.

Impact on control programs for powdery mildew. Precise definition of the onset of ontogenic resistance allows us to optimize fungicide application schedules, targeting the period of highest fruit susceptibility with the most effective fungicides. Understanding the mechanism of this resistance and its impact on fungal development aids in predicting epidemics in the field so we can adjust application schedules accordingly. Interaction with other microorganisms, such as $B$. cinerea and spoilage organisms, need to be considered in order to ensure production of clean fruit and wine of high quality.

After investing billions of dollars in the development of fungicides with remarkable efficacy and safety, it is especially unfortunate that we are faced with the loss of compounds like the demethylation inhibitor and strobilurine fungicides due to pathogen resistance. Development of fungicide resistance is rather common in powdery mildews, which have always been among the first pathogens to exhibit field resistance to fungicides. With the combined threat of pathogens developing resistance to the newest and best fungicides, with changes in their host range, and with the overcoming of major resistance genes in important crops, it is critical to consider all components involved in the disease triangle. Ontogenic resistance represents an additional tool that can be exploited to better manage plant diseases and mitigate many of the risks associated with disease management solely based on chemical input.

\section{ACKNOWLEDGMENTS}

This research was supported by the USDA/FAS/OICD/RSED competitive grants program, by the USDA Viticulture Consortium, the New York Wine and Grape Foundation, and the Kaplan Fund. We thank I. Dry of the Commonwealth Science and Industrial Research Organisation, at the University of Adelaide, Waite Campus, who hosted the author as a visiting scholar at the CSIRO laboratory on four occasions from 1998 to 2001 to complete the molecular studies on ontogenic resistance, and M. Goffinet and M. J. Welser who assisted with the anatomical studies.

\section{LITERATURE CITED}

1. Aist, J. R. 1976. Papillae and related wound plugs of plant cells. Annu. Rev. Phytopathol. 14:145-163.

2. Aylor, D. E. 1998. The aerobiology of apple scab. Plant Dis. 82:838849.

3. Cooley, D. R., Wilcox, W. F., Kovach, J., and Schloemann, S. G. 1996. Integrated pest management programs for strawberries in the Northeastern United States. Plant Dis. 80:228-237.

4. Delp, C. J. 1954. Effect of temperature and humidity on the grape powdery mildew fungus. Phytopathology 44:615-626.

5. Falk, S. P., Gadoury, D. M., and Seem, R. C. 1996. Impact of ontogenic resistance and fenarimol on seasonal development of scab on apple foliage. (Abstr.) Phytopathology 86(suppl.):S85-86.

6. Gadoury, D. M., Ficke, A., Seem, R. C., Wilcox, W. F., and Dry, I. B. 2000. Ontogenic resistance to powdery mildew (Uncinula necator) in 
grape berries. Proc. Int. Symp. Cool Climate Vitic. Oenol., 5th. Melbourne, Australia.

7. Gadoury, D. M., and Seem, R. C. 1995. Development of ontogenic resistance to powdery mildew (Uncinula necator) in fruit of Concord grapevines. (Abstr.) Phytopathology 85:1149.

8. Gadoury, D. M., Seem, R. C., Ficke, A., Wilcox, W. F., and HenickKling, T. 2000. Diffuse infections of Uncinula necator predispose grape berries to bunch rot and spoilage microorganisms, and degrade wine quality. (Abstr.) Phytopathology 90(suppl.):S26.

9. Gadoury, D. M., Seem, R. C., Pearson, R. C., Wilcox, W. F., and Dunst, R. M. 2001. Effects of powdery mildew on vine growth, yield, and quality of Concord grapes. Plant Dis. 85:137-140.

10. Gadoury, D. M., Seem, R. C., and Stensvand, A. 1995. New developments in forecasting the risk of apple scab. N.Y. Fruit Q. 2:5-8.
11. Gadoury, D. M., Seem, R. C., Stensvand, A., and Falk, S. P. 1996. Minimum criteria for infection by Venturia inaequalis, and severity of scab at different phenological stages. (Abstr.) Phytopathology 86(suppl.): S122.

12. Gadoury, D. M., Seem, R. C., and Wilcox, W. F. 1997. Early ontogenic resistance to powdery mildew in Chardonnay and Riesling grapes. (Abstr.) Phytopathology 87(suppl.):S31.

13. Gadoury, D. M., Seem, R. C., and Wilcox, W. F. 2000. The early development of ontogenic resistance to powdery mildew in fruit of Vitis labruscana and Vitis vinifera grapevines. Proc. Int. Workshop Grapevine Downy and Powdery Mildew, 3rd. SARDI Res. Rep. Ser. 50:111-112.

14. Schweizer, P., Christoffel, A., and Dudler, R. 1999. Transient expression of members of the germin-like gene family in epidermal cells of wheat confers disease resistance. Plant J. 20:541-552. 